\title{
Zooplankton biodiversity and community structure vary along spatiotemporal environmental gradients in restored peridunal ponds
}

\author{
María ANTÓN-PARDO, ${ }^{*}$ Xavier ARMENGOL,${ }^{2}$ Raquel ORTELLS ${ }^{2}$ \\ ${ }^{1}$ Biology Centre AS CR v.v.i., Institute of Hydrobiology, Na Sádkach 7, 37005 České Budějovice, Czech Republic; ${ }^{2}$ Microbiology \\ and Ecology Department/ICBiBE, University of Valencia, A.O. 22085, 46071 Valencia, Spain \\ *Corresponding author: anparma@uv.es
}

\begin{abstract}
Zooplankton assemblages in neighboring ponds can show important spatial and temporal heterogeneity. Disentangling the influence of regional versus local factors, and of deterministic versus stochastic processes has been recently highlighted in the context of the metacommunity theory. In this study, we determined patterns of temporal and spatial variation in zooplankton diversity along one hydrological year in restored ponds of different hydroperiod and age. The following hypotheses regarding the assembling of species over time were tested: i) dispersal is not limited in our study system due to its small area and high exposure to dispersal vectors; ii) community dissimilarity among ponds increases with restoration age due to an increase in environmental heterogeneity and stronger niche-based assemblages; and iii) similarity increases with decreasing hydroperiod because hydroperiod is a strong selective force filtering out organisms with long life cycles. Our results confirmed dispersal as a homogenizing force and local factors as gaining importance with time of restoration. However, short hydroperiod ponds were highly dissimilar, maybe due to the environmental differences among these ponds, or to high stochasticity followed by priority effects under a weak selection pressure. By adding a temporal dimension to the study of zooplankton structuring, we could identify the first months after flooding as being crucial for species richness, especially in short hydroperiod ponds; and we detected differences in seasonal species richness related to hydroperiod and pond age.
\end{abstract}

Key words: Crustaceans; dispersal; diversity; metacommunity dynamics; rotifers; similarity, singularity.

Received: July 2015. Accepted: October 2015.

\section{INTRODUCTION}

Small ponds (less than $1 \mathrm{~km}^{2}$ ) are the most widespread waterbodies on Earth, but their ecological value has traditionally been neglected (De Meester et al., 2005). Yet, these small ecosystems contribute greatly to regional diversity, largely because of their abundance and compositional dissimilarity among sites (Oertli et al., 2002; Williams et al., 2004). However, studies on the influence of local coupled to regional factors on biodiversity and community structure of ponds are still an urgent demand (Oertli et al., 2009; Lemmens et al., 2013). The relevance of regional analyses arose after the development of studies on aquatic metacommunities, a set of interacting communities linked by dispersal (Leibold et al., 2004). The resulting communities should differ depending on the number of species that exchange, related to their dispersal capability (source-sink dynamics or mass effects; Leibold et al., 2004) and to regional characteristics that may affect the likelihood of arrival (connectivity, abundance of source habitats or regional species pool; De Meester et al., 2005). Pond biodiversity can be thus reduced when dispersal rates are limited, when geographical barriers make difficult the arrival of new species or when regional diversity is low. This should reduce similarity and in- crease the possibility of unique species (i.e., rarity) among ponds in a metacommunity (Leibold et al., 2004) increasing in turn beta-diversity over the region.

In addition to regional factors, local factors may increase differences among patches through species sorting, as they determine the adequate conditions for a species to establish in the new habitat (Caley and Schluter, 1997; Chase, 2003). These include biotic interactions (Blaustein, 1998; Shurin and Allen, 2001), tolerance ranges and resource availability (Armengol and Miracle, 1999; Frisch et al., 2006; Waterkeyn et al., 2008). A crucial abiotic condition is water permanence or hydroperiod, as it is one of the most recurrent variables explaining invertebrate community structure (Wellborn et al., 1996; Boix et al., 2007, 2008; Waterkeyn et al., 2008). When ponds are temporary, the period of time when the pond holds water determines the survival of organisms with a certain life cycle length (Grillas et al., 2004), so ponds with longer hydroperiod have usually higher species richness (Schneider and Frost, 1996; but see e.g. Lopes et al., 2014). On the other hand, differences among ponds do not need a deterministic cause. Stochastic processes such as ecological drift or random extinction (Hubble, 2001) may have strong effects on community assemblages. In addition, the order in which a series of species arrive to a given habitat can have 
strong effects on community composition (priority effects), resulting in the resident community inhibiting the establishment of later immigrants, which explains much of the regional variation among ponds (Leibold et al, 2004, Louette and De Meester, 2007). Moreover, variation in historical colonization processes leading to priority effects, including the arrival and establishment of predators, is thought to be a primary mechanism creating variation among communities (Chase, 2003).

When investigating the relative importance of determinant processes for metacommunity assemblages, an additional difficulty is that it may change with time (Mouquet et al., 2003). Particularly considering zooplankton assemblages, successional change may become substantial even within a year (Lampert and Sommer, 2007) because their short generation times yields to an efficient response to species sorting and priority effects (Fukami, 2004; Kneitel and Chase, 2004). One possibility to examine how the interaction of local and regional processes changes over time is following the trajectories of community assembly in recently-created habitats (Allen et al., 2011). It has been suggested that the influence of local processes (i.e., species sorting) gain importance over spatial structures (i.e., priority effects) with the age of the ecosystem (Allen et al., 2011). It is important to note that organisms inhabiting temporary ponds survive dry periods as resting stages that accumulate in the sediment forming egg banks. These egg banks represent a biodiversity reservoir that increases with the age of the ecosystem and buffers extinction (Brendonck and De Meester, 2003). On the other hand, if ponds are of the same age, then the length of the hydroperiod plays an important role in determining the relative importance of stochastic and/or priority effects. In a manipulative experiment, Chase (2007) found that drought increased community similarity by acting as an environmental harsh filter and making the community more niche-assembled.

Malladas de El Saler is a set of peridunal ponds (dune slacks) restored at different moments during the last 28 years and with different hydroperiod lengths. In a previous study on a group of selected ponds, we identified a total of 100 taxa (Antón-Pardo and Armengol, 2010). The one-year study revealed hydroperiod, conductivity and restoration age as the most relevant factors explaining this community heterogeneity. In the present study we wanted to exploit our fortnightly data (species number and density) obtained from these ponds in order to find temporal patterns of community change (species turnover) both in the local ponds and from a spatially-structured metacommunity approach. Since the area is small, dispersal is not expected to be a limiting force but a homogenizing one (Waterkeyn et al., 2008). If dispersal is indeed unlimited we should expect, under a scenario of habitat heterogeneity, niche-selective processes accounting for an increase in among-ponds dissimilarity with restoration age (Allen et al., 2011). On the other hand, if hydroperiod length is a strong selective force, we should expect more similar communities with decreasing hydroperiod, by filtering out species with long-life cycles from the regional pool (Chase, 2007). We will explore these three hypotheses in our study area: 1) dispersal is not limited, 2) older ponds are more dissimilar; and 3) ponds with shorter hydroperiod are more similar. Although elucidating the relative importance of stochastic versus deterministic processes is beyond our goal, understanding the mechanisms of zooplankton assemblage over time that may be occurring in our system of restored ponds will be highly relevant to nature conservation management and policy. The additional value of our approach is twofold. On one hand, by studying one year in detail, we incorporated intra-annual temporal heterogeneity and quantified species turnover. On the other hand, we included the main groups of zooplankton organisms (rotifers, copepods and branchiopods) which have relevant relationships, an effort that is not frequently found in literature.

\section{METHODS}

\section{Study area}

The study area is located in a sandy stretch that separates the Mediterranean Sea from Albufera de Valencia, a freshwater lagoon (Fig. 1), and it is included in the protected area of the Albufera Natural Park. The selected ponds showed marked differences in environmental variables (conductivity, macrophytes, depth), hydroperiod and restoration age. Two of the ponds were Permanent (P1-PR and P2-98), and six were temporary, but two of them had Long Hydroperiod (flooded during at least six consecutive months; LH1-98 and LH2-03) and four had Short Hydroperiod (intermittent flooding strongly determined by rainfall, with several dry periods per year: SH1-98, SH2-03, SH3-PR and SH4-98). The area was heavily altered in the 60's due to an urban development plan, but since the late 80 's several restoration programs have been carried out in the now protected area. Some consecutive projects (from the local government and EU project, Life Duna: 2001-2004) engaged in restoring the area by digging new ponds in their silted old basins. Four of them were created in 1998 (P2-98, LH1-98, SH1-98 and SH4-98), and two in 2003 (LH2-03 and SH2-03). Additionally in 2003, two ponds were Partially Restored by widening two small previous water bodies, (P1-PR and SH3-PR, here considered the oldest ponds because they were not totally silted in the 60 's). In addition, some plant and fish species were introduced in the permanent pond (P1-PR). Only the permanent ponds (P1-PR and P2-90) hold fish communities, dominated by small-size species [Aphanius iberus (Valenciennes, 1846), introduced with conservation aims; and Gambusia holbrooki Girard, 1859, accidentally 
introduced], but all ponds house the amphibian species Rana perezi (Lopez-Seoane, 1885). Tab. 1 summarizes some characteristics of the studied ponds. Further information on the study area is described elsewhere (Antón-Pardo and Armengol, 2010; Olmo et al., 2012; Ortells et al., 2012; Antón-Pardo et al., 2013).

\section{Sampling}

Environmental variables (including nutrient and chlorophyll $a$ concentration) were determined fortnightly, from November 2006 -first inundation of temporary ponds after summer drought- to July 2007 as long as the ponds held water. Conductivity, temperature, $\mathrm{pH}$, oxygen concentration and depth were measured in situ, while 1-L water sam- ples were taken for subsequent analyses of chlorophyll $a$, phosphate and nitrate concentrations. Mean values of environmental variables and their range (minimum and maximum) are shown in Supplementary Tab. 1. On each date and pond, zooplankton was taken in an integrated sample obtained from different sites of each pond to include all possible microhabitats. To do so, a known volume of water (between 6 and $10 \mathrm{~L}$ ) was taken using a $1 \mathrm{~L}$ jar and filtered through a $35 \mu \mathrm{m}$ mesh-size net. After fixation with formalin $4 \%$, organisms were identified and counted using an inverted microscope. The individuals were identified until species level when possible following Koste (1978) for rotifers, Dussart (1969) for copepods, and Alonso (1996) and Amorós (1984) for branchiopods.

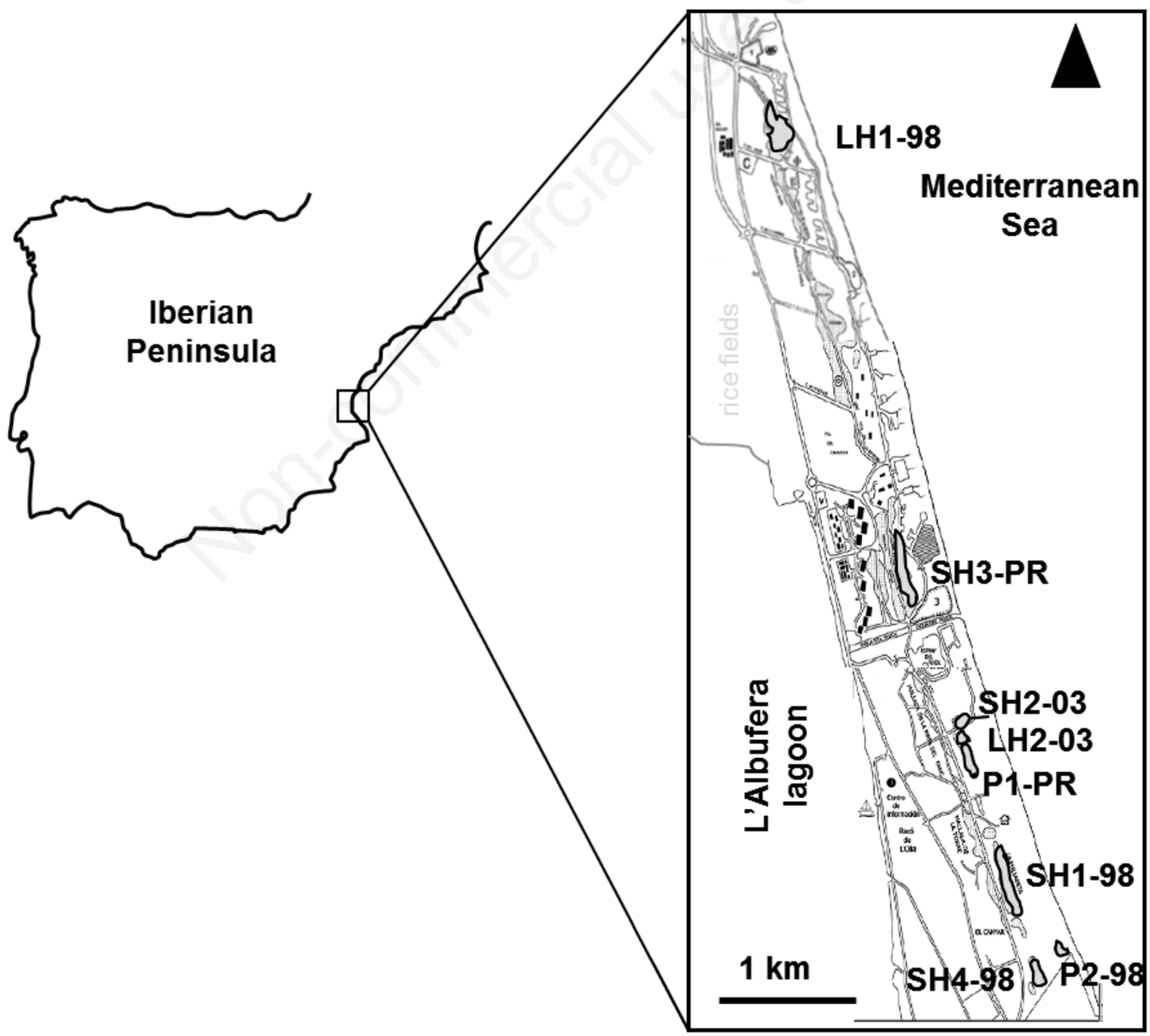

Fig. 1. Map of the study site with the location of the eight ponds studied. 


\section{Data analyses}

At a local scale, species richness per visit and cumulative richness (the sum of all zooplankton species found in each pond during the study period) were used to graphically represent the temporal pattern of each pond. Differences in mean zooplankton richness for the group of ponds according to hydroperiod [permanent $(\mathrm{P})$, long hydroperiod $(\mathrm{LH})$, and short hydroperiod (SH)] and restoration [partially restored (PR), created in 1998 (1998); and created in 2003 (2003)] were tested for each season (autumn: November and December; winter: January and February; and spring: March to June; summer was not considered, as only the permanent ponds had water), with Kruskall-Wallis analysis and post-hoc Mann-Whitney pairwise tests.

i) Two parameters were calculated to assess rarity:

- singularity (s), the uniqueness of the set of species in each pond (Boix et al., 2007):

$$
s=(e / S) \cdot 100
$$

where $e$ is the number of species exclusively found in one pond during all the study period, and $S$ is the total number of species in that pond.

- Index of Faunal Originality (IFO; Puchalski, 1987), which considers the occurrence of each species in the study area:

$$
I F O=\left(\Sigma 1 / M_{i}\right) / S
$$

where $M_{i}$ is the total number of ponds where the species $i$ was found, and $S$ is the total number of species in that pond.

At a metacommunity scale, we quantified pond differences with beta diversity values (BD) following Legendre and De Cáceres (2013). BD values were estimated as the total variance of the community composition matrix (with chord-transformed species data) calculated from the total sum of squares of the abundance matrix. This index, which is independent of the values of alpha and gamma diversity, was computed both spatially -considering the average value of density for each species in the set of ponds over the study period- and temporally -considering taxa densities in each sampling for each pond as a surrogate for species turnover. $\mathrm{BD}$ values range from 0 (highly similar) to 1 (highly dissimilar). In addition, BD was partitioned in Local Contribution to Beta Diversity (LCBD) coefficients which were used as indicators of the ecological uniqueness of each site and date in terms of community composition, indicating sampling units (sites/dates) with special conservation interest or with rare species combinations (Legendre and De Cáceres, 2013). These coefficients were calculated under the two approaches described above (spatial and temporal) and their significance was tested after 999 permutations. The analyses were performed using $\mathrm{R}$ 3.1.3 program ( $\mathrm{R}$ Core Team, 2015). The relationships between LCBD obtained for the spatial analysis and local parameters (cumulative species richness, species richness per visit, singularity and IFO) were explored with Spearman correlations.

ii) Additionally, two parameters were calculated to assess similarity:

- Simpson similarity Index (SI), the differences in species composition on each sampling date between pairs of ponds:

$$
S I=M / S_{\min }
$$

where $M$ is the number of species coincident in two ponds, and $S_{\min }$ is the total number of species from the pond with less taxa. This index ranges from 0 (different communities in the two ponds) to 1 (high similarity between the communities).

- Chord distance, which considers the species mean density over the sampling period:

$$
\text { chord distance }=\sqrt{\left[2-2\left(\frac{\Sigma x_{j i} x_{k i}}{\left.\sqrt{\left(\Sigma x_{j i}^{2} \Sigma x_{k i}^{2}\right)}\right)}\right)\right]}
$$

Tab. 1. Pond characteristics and number of samples (N) taken in the eight ponds studied (from November 2006 to July 2007).

\begin{tabular}{lccccc} 
& Hydroperiod & Restoration & Maximum surface $\left(\mathrm{m}^{2}\right)$ & $\begin{array}{c}\text { Distance to the } \\
\text { closest-furthest pond }(\mathrm{m})\end{array}$ \\
P1-PR & Permanent & $2003(\mathrm{PR})$ & 4005 & $5-5750$ & 14 \\
P2-98 & Permanent & 1998 & 955 & $250-7500$ & 14 \\
\hline LH1-98 & Long & 1998 & 19700 & $4100-7850$ & 12 \\
LH2-03 & Long & 2003 & 2100 & $5-5700$ & 7 \\
\hline SH1-98 & Short & 1998 & 7770 & $400-7000$ & 9 \\
SH2-03 & Short & 2003 & 4138 & $50-5500$ & \\
\hline SH3-PR & Short & $2003(\mathrm{PR})$ & 6529 & $1400-4100$ & \\
SH4-98 & Short & 1998 & 1342 & $250-7850$ & 6 \\
\hline
\end{tabular}

$P R$, partially restored old pond (see text). 
where $x_{j i}$ is the density of the species $i$ in the community $j$, and $x_{k i}$ is the density of the same species in the community $k$. This parameter is maximum when the species found at two sites are completely different. We tested the correlation between both similarity values and the minimum geographical distance between pairs of ponds with a Mantel test.

The differences among groups of ponds [hydroperiod (P, LH and SH) and age categories (PR, 1998 and 2003)] in relation to both i) rarity, and ii) Simpson similarity index, were analyzed with Kruskal-Wallis tests, and pairwise Mann-Whitney tests. All the above mentioned statistical analyses were performed using PAST 1.81 (Hammer et al., 2008). Spatial variables were obtained through distancebased Moran Eigenvector Maps (dbMEM) using the matrix of the UTM coordinates for each pond, following the procedure described in Dray et al. (2006). The significance of each spatial vector (seven MEM's) was tested with 99 permutations, and the significant vectors were selected for the subsequent analysis. To test the relative influence of these spatial factors versus the most relevant environmental factors (conductivity, depth, oxygen concentration and chlorophyll $a$ according to Antón-Pardo and Armengol, 2010) on cumulative richness, singularity and IFO, we used partial multiple regressions, and the variance explained by environmental, spatial and both variables was calculated (adjusted $\mathrm{R}^{2}$ ). The selected models were the ones with the lowest AIC (Akaike Information Criterion). Variables were inverse-transformed to meet normality when required. This analysis was performed using R 3.1.3 program (R Core Team, 2015).

\section{RESULTS}

During all the study period, 71 rotifer taxa, 14 cladocerans, 11 copepods, and one anostracan were found (Supplementary Tab. 2). Species richness increased monotonously over the year, except for a slight decrease in winter and spring in the permanent ponds and an increase at the same time in the long hydroperiod ponds (Fig. 2). Despite several intermittent dry periods, SH ponds normally reached a high number of species immediately after each flooding event. The cumulative richness curves along the study period (Fig. 2) increased with different slopes among ponds, being P1-PR and LH1-98 the steepest and P2-98, SH2-03 and SH3-PR the most gradual.

In every season, the number of species normally increased with the length of hydroperiod and with restoration age (Tab. 2). In autumn, the permanent ponds had the highest richness and decreased along the seasons, but they were always richer than the short hydroperiod ponds. When considering restoration age, the partially restored ponds (P1PR, SH3-PR) were comparable in species richness to the new ponds except in spring and the ponds restored in 1998 were the richest in winter. In contrast to new ponds, which maintained similar levels throughout the year, richness values in winter decreased in the partially restored ponds but increased in the ones restored in 1998.

Overall, cumulative species richness was higher in permanent ponds (P: 40-62) than in temporary ponds (LH and SH: 18-39; Fig. 3a). Rotifers were the group with the highest number of species in all ponds, whereas the maximum cladoceran richness appeared in P1-PR. The highest rarity values for all the community (singularity and IFO) were found in the permanent ponds (Fig. 3b). Among the short hydroperiod ponds, singularity in SH1-98 was high and similar to P2-98, the permanent pond restored at the same time. LH1-98 had the lowest number of exclusive species but high IFO, meaning that the species present in this pond were found in very few ponds. However, no significant differences were found in singularity or IFO among ponds grouped by their hydroperiod or restoration age.

The value of beta-diversity (BD), calculated for all the ponds, was 0.77 , and none of the spatial-LCBD coefficients were statistically significant (Fig. 4a). Similarly, no correlation was found between LCBD coefficients and richness $\left(\mathrm{R}^{2}=0.005\right)$ or rarity indices (singularity: $\mathrm{R}^{2}=2 * 10^{-5}$; IFO: $\left.\mathrm{R}^{2}=0.011\right)$. In the temporal analysis, temporal $\mathrm{BD}$ in each pond along the study period ranged from 0.56 in SH4-98 to 0.91 in SH1-98 (Fig. 4b), and local contribution values to temporal differences (temporal LCBD) were significant on the first sampling date after pond filling in three temporary ponds (LH1-98, SH2-03, SH4-98) and in two different occasions in one permanent pond (P2-98).

Tab. 2. Mean seasonal richness for each group of ponds according to hydroperiod and to restoration age, and P-values for Mann-Whitney pairwise comparisons.

\begin{tabular}{lcccccccc} 
& \multicolumn{3}{c}{ Hydroperiod } & & P-value & \multicolumn{3}{c}{ Restoration age } \\
Season & P & LH & SH & & PR & 1998 & 2003 & \\
Autumn & $18.2^{\mathrm{a}}$ & $8.2^{\mathrm{b}}$ & $7.9^{\mathrm{b}}$ & $<0.01$ & $13.3^{\mathrm{a}, \mathrm{b}}$ & $11.9^{\mathrm{a}}$ & $6.0^{\mathrm{b}}$ & $<0.05$ \\
Winter & $13.1^{\mathrm{a}}$ & $11.9^{\mathrm{a}, \mathrm{b}}$ & $9.3^{\mathrm{b}}$ & $<0.05$ & $9.7^{\mathrm{a}}$ & $14.0^{\mathrm{b}}$ & $6.9^{\mathrm{a}}$ & $<0.01$ \\
\hline Spring & $13.0^{\mathrm{a}}$ & $11.9^{\mathrm{a}}$ & $7.5^{\mathrm{b}}$ & $<0.05$ & $14.6^{\mathrm{a}}$ & $10.6^{\mathrm{a}, \mathrm{b}}$ & $7.3^{\mathrm{b}}$ & $<0.01$ \\
\hline
\end{tabular}

P, permanent; LH, long hydroperiod; SH, short hydroperiod; PR, partially restored; restored in 1998 and restored in 2003; a,b different letters indicate different groups $(P<0.05)$. 

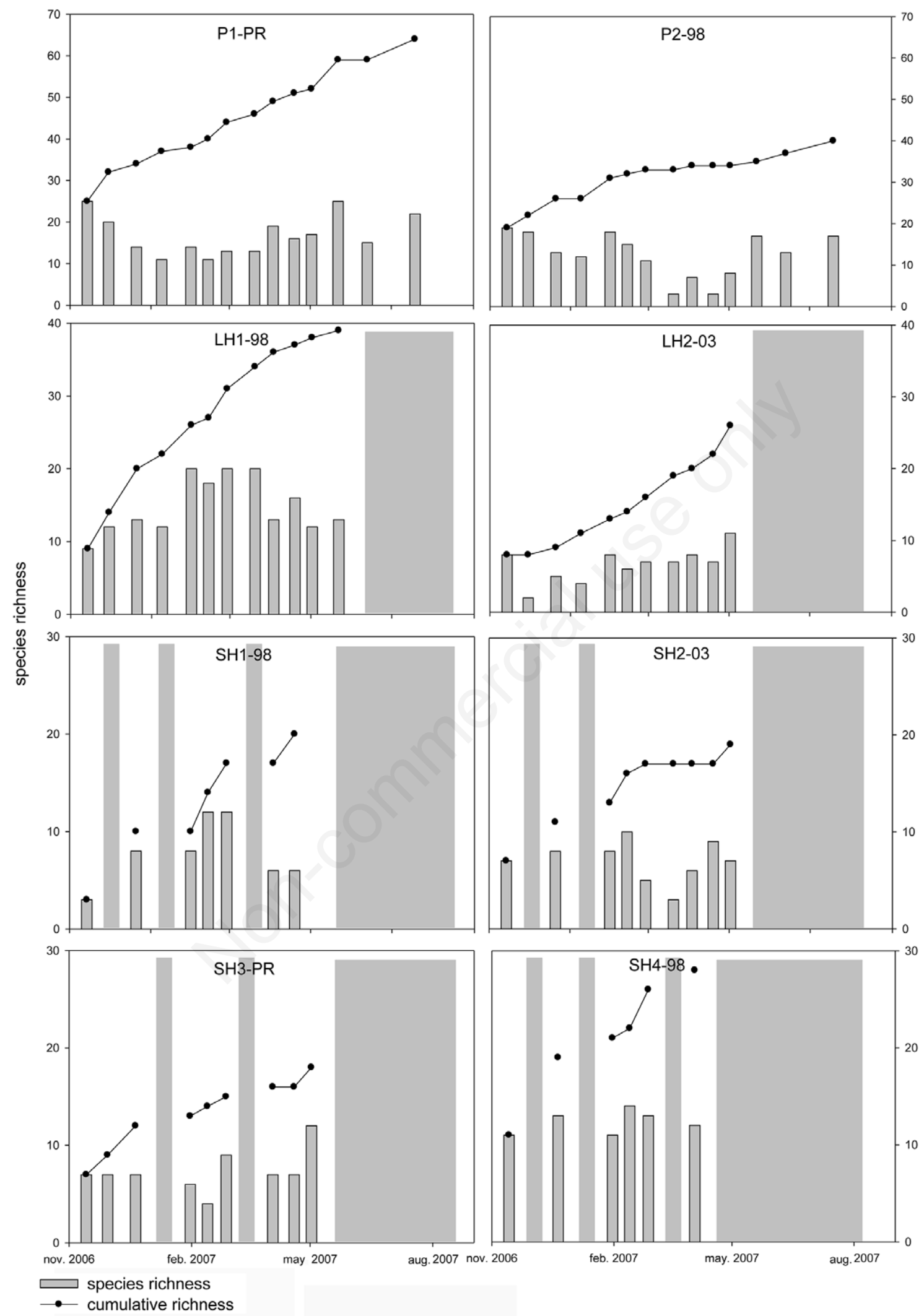

Fig. 2. Species richness per visit (grey bars) and cumulative species richness (line-dots) in the permanent (P1-PR and P2-98), long hydroperiod (LH1-98 and LH2-03) and short hydroperiod (SH1-98 to SH4-98) ponds. Note that different scales are used for the different groups of ponds. Bars are not equidistant because they correspond to actual sampling dates. Grey areas represent dry events. 
Simpson similarity index (Fig. 5a) based on zooplankton assemblages was higher between the permanent ponds $(\mathrm{SI}=0.55)$ than between the temporary ponds with long and short hydroperiod $(\mathrm{SI}=0.35 ; \mathrm{P}<0.01$ and $\mathrm{SI}=0.43$; $\mathrm{P}<0.05$, respectively). According to restoration age (Fig. $5 b)$, assemblages were more similar in the newer ponds $(\mathrm{SI}=0.64)$ than in the rest of ponds (partially restored ponds: $\mathrm{SI}=0.38 ; \mathrm{P}<0.05$; ponds from 1998: $\mathrm{SI}=0.35$; $\mathrm{P}<0.01)$. Mantel test showed no correlation between similarity (Simpson Index: $\mathrm{R}^{2}=0.003$; and chord distance: $\left.\mathrm{R}^{2}=0.037\right)$ and geographic distance between the ponds.

Out of the seven spatial variables obtained in the Moran Eigenvector Maps, four of them were significant: the first two and the last two. Partial multiple regression showed that for IFO and richness, only environmental variables contributed to the variance, and none of the MEM's $(67.38 \%$ with depth and oxygen as selected variables for IFO, and $78.82 \%$ with depth and conductivity for richness; Tab. 3). For singularity, depth and three spa- tial factors were selected for the model (all with a negative influence except the second spatial factor), with a contribution of $0.06 \%$ by environmental variables, $21.84 \%$ by spatial ones, and $9.85 \%$ by their interaction. Only the models for IFO and richness were significant $(\mathrm{P}<0.05)$.

\section{DISCUSSION}

The spatial configuration of the ponds did not correlate with zooplankton assemblage similarity or clearly explained species singularity, confirming our expectation that dispersal is unlimited and that local factors in our system are more relevant than regional ones. Besides the short distance among the study ponds (maximum $8 \mathrm{~km}$ ) and the apparent absence of geographical barriers, the occurrence of zooplankton dispersal vectors (such as waterbirds, humans or wind; Bilton et al., 2001; Waterkeyn et $a l ., 2010)$ in the area was frequently observed. Resistant stages of zooplankton organisms have in general high dis-
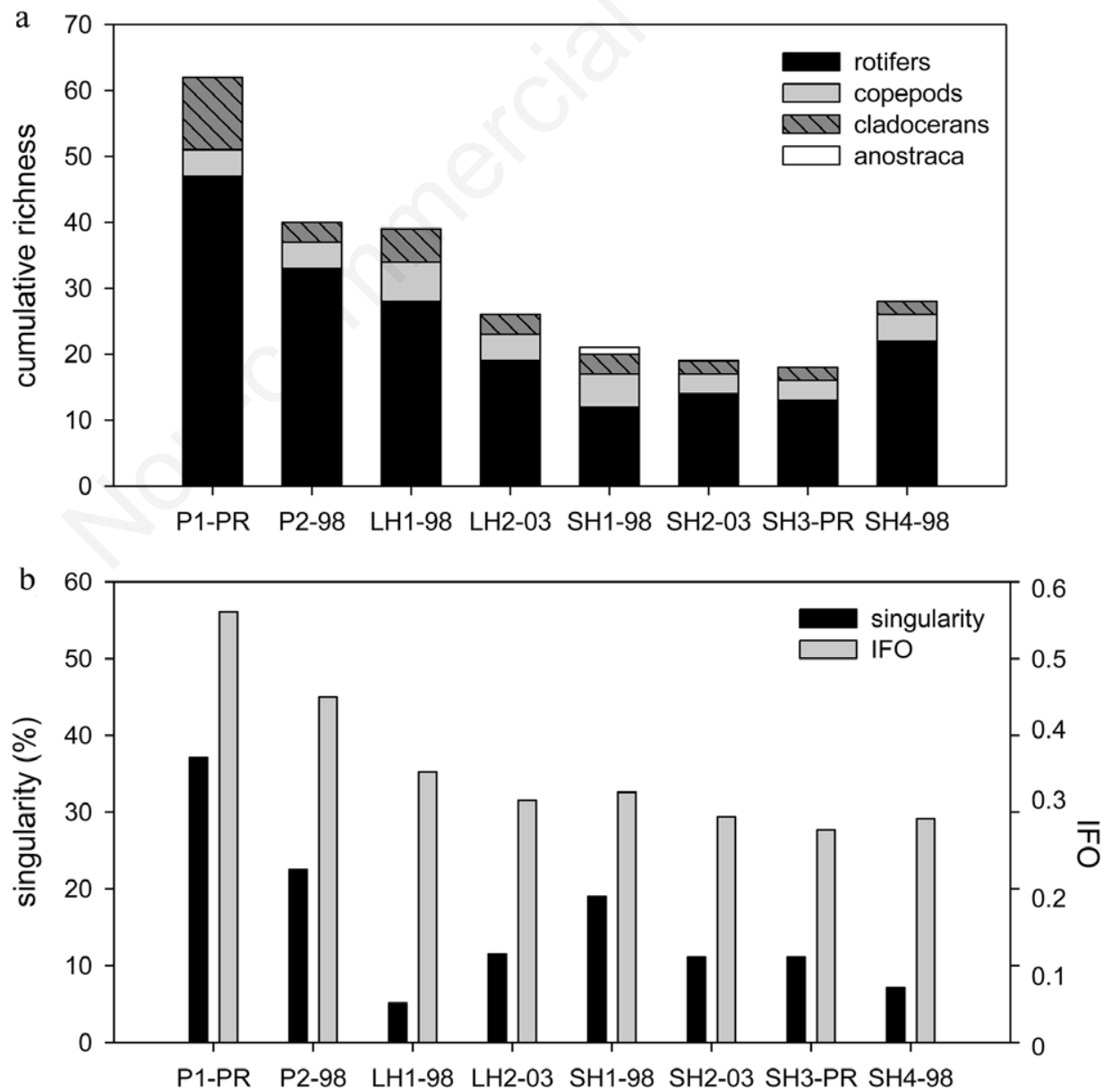

Fig. 3. a) Cumulative species richness of the main zooplankton groups. b) Diagram of rarity parameters [singularity and index of faunal originality (IFO)] in each pond. 
persal capabilities and can colonize new habitats in a very short time (Louette and De Meester, 2005; Frisch et al., 2007). Our conclusions agree with other studies performed in similar spatial scales, where local factors determine species richness and community structure on permanent and temporary ponds despite high dispersal (Cottenie et al., 2003; Waterkeyn et al., 2008; Audet et al., 2013; Mimouni et al., 2015).

All ponds increased gradually in cumulative species richness along the study period. The new species may have come either from external sources or by egg hatching from the sediment bank (Ortells et al., 2012). However, since no pond seemed to have reached saturation, we suspect that not only dispersal is important, but also must regional diversity be high. Under this scenario of high dispersal, and given that ponds are environmentally heterogeneous due to differences in conductivity, depth, oxygen, macrophytes and predation (Antón-Pardo and Armengol, 2010), we may expect a strong influence of mass or priority effects of initial colonizers after pond creation (Shurin, 2000; Leibold et al., 2004; Louette and De Meester, 2007), followed by a shift to control by niche processes later in time (Allen et al., 2011) which should result in higher dissimilarities among more mature, established zooplankton communities. Indeed, similarity decreased with restoration age in our system. Other studies have reported high similarity among pioneer communities in areas where dispersal was not limited (Louette and De Meester, 2005; Allen et al., 2011).

In contrast, results on hydroperiod length were not in agreement with our expectations. It has been postulated that drought acts as a strong selective pressure filtering species out and resulting in more similar, niche-assembled communities (Chase, 2007). However, we found short hydroperiod ponds less similar in species composition, as observed in another study of urban ponds drained of water during winter (Pinel-Alloul and Mimouni, 2013; Mimouni et al., 2015). One possible explanation may rely in the environmentally different short-hydroperiod ponds, where its shortlived inhabitants are more selected on the basis of conditions in the water column rather than on drought itself. In fact, they hold the largest differences in conductivity: 5.5 $\mathrm{mS} \mathrm{cm}{ }^{-1}$ between SH3-PR and SH4-98. This environmental differences may be the cause of the relatively high number of rare species, which suggests specialization to particular local conditions. Another possibility is that hydroperiod was not long enough for a strong selection to take place, and thus ecological stochasticity and priority effects were responsible for their dissimilarities (Leibold et al., 2004). This would explain that in these ponds, a high number of new species was detected after each inundation event. Every time the ponds filled, resting stages from the egg bank could have had similar possibilities to hatch, and stochastic colonization may have resulted in a considerable site-to-site variation in their composition. In a similar manner to what may have occurred through restoration age, as communities assemble along the hydroperiod, not only possibilities for establishment increase but also the importance of competition and predation (Schneider and Frost, 1996). In permanent and longer hydroperiod habitats, local factors would then strongly influence the richness or rarity of species (Allen et al., 2011), which increased with hydroperiod in our study system. However, the influence of local factors is not always straightforward, as counteracting ef-
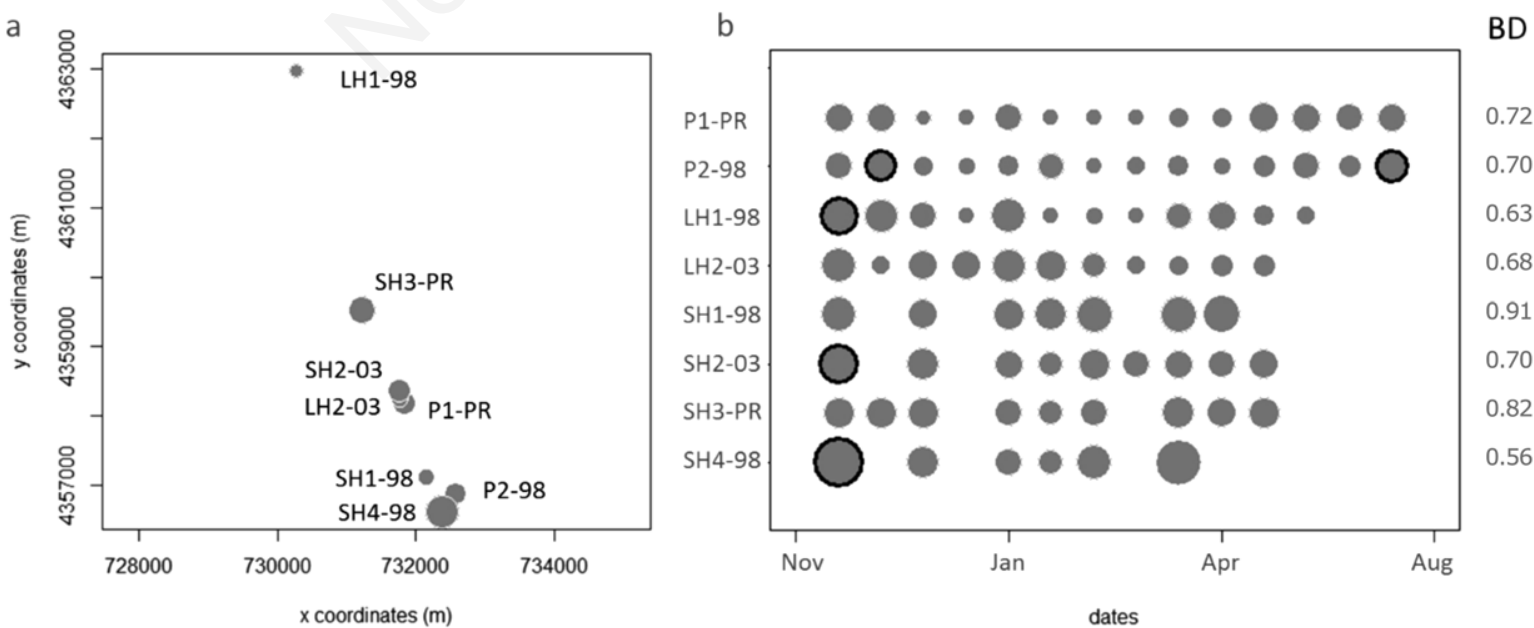

Fig. 4. a) Map of LCBD (Local Contribution to Beta Diversity) in the eight studied ponds (see Fig. 1); b) Space-time maps of LCBD values in the ponds along the study period; BD column indicates the beta diversity values calculated as the rate of species turnover in each pond. The circle surfaces are proportional to the LCBD values. Circles with a black edge indicate significant values at $\mathrm{P}<0.05$. 
fects may produce synergisms that blur a specific pattern. For example, the presence of fish in the permanent ponds selectively feeding on large species (Wellborn et al., 1996; Antón-Pardo and Armengol, 2014) could be counteracted by the development of vegetation in these ponds which can be used as refuge against fish predation (Burks et al., 2002).

Metacommunity studies are often constrained to snapshot patterns of abundance. By adding a temporal dimension to the study of zooplankton structuring, the relative importance of changes through time could be detected. For example, according to our results, and in agreement with other studies in the area (Olmo et al., 2012), the first filling after the longest dried period (summer) revealed high relevance for community dissimilarities within ponds. The high LCBD coefficients observed have been related with a great uniqueness of species composition (Legendre and De Cáceres, 2013), and may be supporting the idea of a high stochasticity on hatching. In addition, we have detected differences in the seasonal species richness related to hydroperiod and age. Thus, intra-annual variation has revealed an added value for building up future knowledge on community assemblage, especially in changing habitats with unpredictable flooded and dried phases as the ones here studied.

\section{CONCLUSIONS}

Altogether, the temporal monitoring of aquatic ecosystems and the comparison of habitats of different age, can help understanding the mechanisms underlying community variations at short times (one year), as well as the community divergence through longer time (decades). In our study area of 8 ponds with relatively high environmental heterogeneity, dispersal was unlimited and local factors may have played a relevant role in community structuring. We found that similarity decreased with age but increased with hydroperiod. This contrasting result may obey to the timescale considerations. A possible scenario is that during the community assembly along the hydroperiod, stochastic colonization may account for pond dissimilarity, whereas the homogenizing force of dispersal may be explaining the increase in similarity. Over time, however, niche-selective forces may have resulted in community divergence via species sorting in the different ponds.

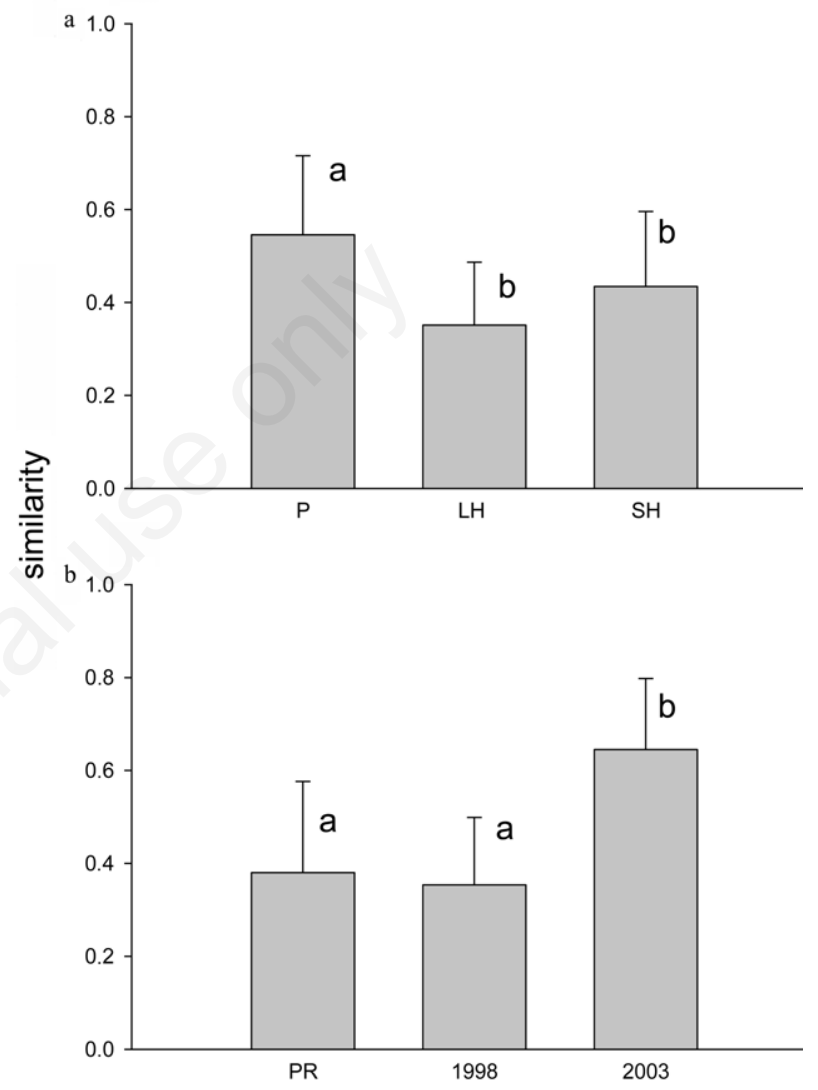

Fig. 5. Mean Simpson similarity indices according to: a) hydroperiod (Permanent, Long Hydroperiod, Short Hydroperiod); and b) restoration age [Partially Restored (PR); restored in 1998, restored in 2003]. Significant differences between groups $(\mathrm{P}<0.05)$ are indicated by lowercase letters.

Tab. 3. Variance explained by the variables (environmental and spatial) in the partial multiple regressions for the three community parameters: singularity, IFO and cumulative species richness.

\begin{tabular}{|c|c|c|c|c|c|c|}
\hline & \multicolumn{2}{|c|}{ Singularity } & \multicolumn{2}{|c|}{ IFO } & \multicolumn{2}{|c|}{ Cumulative richness } \\
\hline & $\begin{array}{l}\% \text { Variance } \\
\text { explained }\end{array}$ & $\begin{array}{l}\text { Selected } \\
\text { variables }\end{array}$ & $\begin{array}{l}\% \text { Variance } \\
\text { explained }\end{array}$ & $\begin{array}{l}\text { Selected } \\
\text { variables }\end{array}$ & $\begin{array}{c}\% \text { Variance } \\
\text { explained }\end{array}$ & $\begin{array}{l}\text { Selected } \\
\text { variables }\end{array}$ \\
\hline$[\mathrm{E}]$ & 0.06 & Depth & 67.38 & Depth, oxygen & 78.82 & Depth, conductivity \\
\hline$[\mathrm{E} \cap \mathrm{S}]$ & 9.845 & & 0 & & 0 & \\
\hline [S] & 21.835 & MEM1, MEM2, MEM6 & 0 & & 0 & \\
\hline $1-[\mathrm{E}+\mathrm{S}]$ & 68.26 & & 32.62 & & 21.18 & \\
\hline
\end{tabular}

IFO, index of faunal originality; [E], environmental variables; [S], spatial variables; [E $\cap S]$, variation shared by environmental and spatial variables,

$1-[E+S]$, unexplained variance. 


\section{ACKNOWLEDGMENTS}

We thank Carla Olmo for assistance in the field and in the laboratory, Jose Benavent-Corai, Daniel Ricard and Carlos P. Carmona for statistical advice, and the Oficina Técnica Devesa-Albufera and Generalitat Valenciana for permission to sample. We would like to thank Bernadette Pinel-Alloul and other anonymous reviewers for their helpful comments on a previous version of the manuscript.

The study was funded by Spanish Ministry of Science and Innovation, through the Project CGL2008-03760, and the fellowship AP2005-3298 to MAP.

\section{REFERENCES}

Allen MR, VanDyke JN, Caceres CE, 2011. Metacommunity assembly and sorting in newly formed lake communities. Ecology 92:269-275.

Alonso M, 1996. [Crustacea. Branchiopoda. Fauna Ibérica.7]. [Book in Spanish]. Museo Nacional de Ciencias Naturales, CSIC, Madrid: 486 pp.

Amorós C, 1984. [Crustacés Cladocères. Introduction pratique à la systématique des organismes des eaux continentales françaises].[Book in French]. Association Française de limnologie, Lyon: $63 \mathrm{pp}$.

Antón-Pardo M, Armengol X, 2010. Zooplankton community from restored peridunal ponds in the Mediterranean region (L'Albufera Natural Park, Valencia, Spain). Limnetica 29:133-143.

Antón-Pardo M, Armengol X, 2014. Aquatic invertebrate assemblages in ponds from coastal Mediterranean wetlands. Ann. Limnol. - Int. J. Lim. 50:217-230.

Antón-Pardo M, Olmo C, Soria JM, Armengol X, 2013. Effect of restoration on zooplankton community in a permanent interdunal pond. Ann. Limnol. - Int. J. Lim. 49:97-106.

Armengol J, Miracle MR, 1999. Zooplankton communities in doline lakes and pools, in relation to some bathymetric parameters and physical and chemical variables. J. Plankton Res. 21:2245-261.

Audet C, MacPhee S, Keller W, 2013. Constructed ponds colonized by crustacean zooplankton: local and regional influences. J. Limnol. 72:524-530.

Bilton DT, Freeland JR, Okamura B, 2001. Dispersal in freshwater invertebrates. Annu. Rev. Ecol. Syst. 32: 159-181.

Blaustein L, 1998. Influence of the predatory backswimmer, Notonecta maculata, on invertebrate community structure. Ecol. Entomol. 23:246-252.

Boix D, Sala J, Gascón S, Martinoy M, Gifre J, Brucet S, Badosa A, López-Flores R, Quintana. XD, 2007. Comparative biodiversity of crustaceans and aquatic insects from various water body types in coastal Mediterranean wetlands. Hydrobiologia 584:347-359.

Boix D, Gascon S, Sala J, Badosa A, Brucet S, Lopez-Flores R, Quintana. X, 2008. Patterns of composition and species richness of crustaceans and aquatic insects along environmental gradients in Mediterranean water bodies. Hydrobiologia 597:53-69.

Brendonck L, De Meester L, 2003. Egg banks in freshwater zooplankton: evolutionary and ecological archives in the sediment. Hydrobiologia 491:65-84.
Burks RL, Lodge DM, Jeppesen E, Lauridsen TL, 2002. Diel horizontal migration of zooplankton: costs and benefits of inhabiting the littoral. Freshwater Biol. 47:343-365.

Caley MJ, Schluter D, 1997. The relationship between local and regional diversity. Ecology 78:70-80.

Chase JM, 2003. Community assembly: when should history matter? Oecologia 136:489-498.

Chase JM, 2007. Drought mediates the importance of stochastic community assembly. P. Natl. Acad. Sci. USA 104: 7430-17434

Cottenie K, Michels E, Nuytten N, De Meester L, 2003. Zooplankton metacommunity structure: regional vs. local processes in highly interconnected ponds. Ecology 84:991-1000.

De Meester L, Declerck S, Stoks R, Louette G, Van de Meutter F, De Bie T, Michels E, Brendonck L, 2005. Ponds and pools as model systems in conservation biology, ecology and evolutionary biology. Aquatic Conserv.: Mar. Freshw. Ecosyst. 15:715-725.

Dray S, Legendre P, Peres-Neto PR, 2006. Spatial modelling: a comprehensive framework for principal coordinate analysis of neighbour matrices (PCNM): Ecol. Model. 196:483-493.

Dussart B, 1969. [Les copépodes des eaux continentales d'Europe occidentale. Tome II: Cyclopoïdes et Biologie].[Book in French]. Boubee \& Cie, Paris: 292 pp.

Frisch D, Green AJ, Figuerola J, 2007. High dispersal capacity of a broad spectrum of aquatic invertebrates via waterbirds. Aquat. Sci. 69:568-574.

Frisch D, Moreno-Ostos E, Green AJ, 2006. Species richness and distribution of copepods and cladocerans and their relation to hydroperiod and other environmental variables in Doñana, South-west Spain. Hydrobiologia 556:327-340.

Fukami T, 2004. Assembly history interacts with ecosystem size to influence species diversity. Ecology 85:3234-3242.

Grillas P, Gauthier P, Yavercovski N, Perennou C, 2004. Mediterranean temporary ponds. 1 . Issues relating to conservation, functioning and management. Tour du Valat, France: $120 \mathrm{pp}$.

Hammer O, Harper DAT, Ryan PD, 2008. PAST-Palaentological Statistics, ver 1.81. Sweden.

Hubble SP, 2001. The unified neutral theory of species abundance and diversity. Princeton University Press, Princeton: 377 pp.

Kneitel JM, Chase JM, 2004. Disturbance, predator, and resource interactions alter container community composition. Ecology 85:2088-2093.

Koste W, 1978. [Rotatoria die Rädertiere Mitteleuropas. Monogonta].[Book in German]. Gerbrüder Brontraeger, Berlin: $663 \mathrm{pp}$.

Lampert W, Sommer U, 2007. Limnoecology. 2nd ed. Oxford University Press, Oxford: 336 pp.

Legendre P, De Cáceres M, 2013. Beta diversity as the variance of community data: dissimilarity coefficients and partitioning. Ecol. Lett. 16:951-963.

Leibold MA, Holyoak M, Mouquet N, Amarasekare P, Chase JM, Hooper MF, Holt RD, Shurin JB, Law R, Tilman D, Loreau M, Gonzalez A, 2004. The metacommunity concept: a framework for multi-scale community ecology. Ecol. Lett. 7:601-613.

Lemmens P, Mergeay J, De Bie T, Van Wichelen J, De Meester L, Declerck SAJ, 2013. How to maximally support local and regional biodiversity in applied conservation? Insights from pond management. PLoS One 8:e72538.

Lopes PM, Bini LM, Declerck SAJ, Farjalla VF, Vieira LCG, 
Bonecker CC, Lansac-Toha FA, Esteves FA, Bozelli RL, 2014. Correlates of zooplankton beta diversity in tropical lake systems. PLoS One 9: 109581.

Louette G, De Meester L, 2005. High dispersal capacity of cladoceran zooplankton in newly founded communities. Ecology 86: 53-359.

Louette G, De Meester L, 2007. Predation and priority effects in experimental zooplankton communities. Oikos 116:419-426.

Mimouni El-A, Pinel-Alloul B, Beisner BE, 2015. Assessing aquatic biodiversity of zooplankton communities in an urban landscape. Urban Ecosyst. 18:1353-1372.

Mouquet N, Munguia P, Kneitel JM, Miller TE, 2003. Community assembly time and the relationship between local and regional species richness. Oikos 103:618-626.

Oertli B, Joye DA, Castella E, Juge R, Cambin D, Lachavanne JB, 2002. Does size matter? The relationship between pond area and biodiversity. Biol. Conserv. 104:59-70.

Oertli B, Cereghino R, Hull A, Miracle R, 2009. Pond conservation: from science to practice. Hydrobiologia 634: 1-9.

Olmo C, Armengol X, Ortells R, 2012. Re-establishment of zooplankton communities in temporary ponds after autumn flooding. Does restoration age matter? Limnologica 42:310-319.

Ortells R, Olmo C, Armengol X, 2012. Colonization in action: genetic characteristics of Daphnia magna Strauss (Crustacea, Anomopoda) in two recently restored ponds. Hydrobiologia 689:37-49.

Pinel-Alloul B, Mimouni El-A, 2013. Are cladoceran diversity and community structure linked to spatial heterogeneity in urban landscapes and pond environments. Hydrobiologia 715:195-212.
Puchalski W, 1978. Phytoplankton assemblages in after-exploitation reservoirs. PhD Thesis, Polish Academy of Sciences.

R Core Team. 2015. R: A language and environment for statistical computing. R Foundation for Statistical Computing, Vienna, Austria.

Schneider DW, Frost TM, 1996. Habitat duration and community structure in temporary ponds. J. N. Am. Benthol. Soc. 15: 4-86.

Shurin JB, 2000. Dispersal limitation, invasion resistance, and the structure of pond zooplankton communities. Ecology 81:3074-3086.

Shurin JB, Allen EG, 2001. Effects of competition, predation, and dispersal on species richness at local and regional scales. Am. Nat. 158:624-637.

Waterkeyn A, Grillas P, Vanschoenwinkel B, Brendonck L, 2008. Invertebrate community patterns in Mediterranean temporary wetlands along hydroperiod and salinity gradients. Freshwater Biol. 53:1808-1822.

Waterkeyn A, Vanschoenwinkel B, Elsen S, Anton-Pardo M, Grillas P, Brendonck L, 2010. Unintentional human-mediated dispersal of aquatic invertebrates via foot wear and motor vehicles in a Mediterranean wetland area. Aquat. Conserv. 20:580-587.

Wellborn GA, Skelly DK, Werner EE, 1996. Mechanisms creating community structure across a freshwater habitat gradient. Annu. Rev. Ecol. Syst. 27:337-363.

Williams P, Whitfield M, Biggs J, Bray S, Fox G, Nicolet P, Sear D, 2004. Comparative biodiversity of rivers, streams, ditches and ponds in an agricultural landscape in Southern England. Biol. Conserv. 115:329-341. 